\title{
Congruencia histórica, poética y crítica en Balún Canán, de Rosario Castellanos. Estudio y acercamientos para una relectura.
}

\section{Historical, poetic and critical congruence in Balún Canán, by Rosario Castellanos. Study and approaches for a rereading.}

\author{
Omar Armando Paredes Crespo \\ Universidad Autónoma Metropolitana-Azcapotzalco (MÉXICO) \\ CE: omararmandoparedescrespo@gmail.com ID ORCID: 0000-0003-4451-1200
}

DOI: $\underline{10.32870 / \text { sincronia.axxiii.n76.14b19 }}$

$\mathrm{BY} \cdot \mathrm{NC}$

Esta obra está bajo una Licencia Creative Commons Atribución-NoComercial 4.0 Internacional

Recibido: $17 / 01 / 2019$

Revisado: 21/02/2019

Aprobado: 20/03/2019

\section{RESUMEN}

Este artículo tiene como objetivo identificar y analizar la presencia de datos históricos, poéticos y críticos en Balún Canán, de Rosario Castellanos. Mucho ya se ha estudiado sobre los acercamientos a la vida de la autora, sin embargo, a través de un análisis sociocrítico, este estudio ofrece una visión amplia a otros aspectos como la relación del relato con la historia nacional mexicana, en los que recupera episodios del Cardenismo, la Guerra Cristera y la reforma agraria de los años treinta. Respecto a la congruencia poética y crítica, este estudio demuestra que es la obra con mayor sentido poético en la producción prosística de Castellanos, además de que, en ella, la escritora asume una marcada postura crítica respecto al comportamiento de sus personajes femeninos ante la supremacía masculina, inaugurando, así, una crítica temprana a las sociedades patriarcales de la provincia mexicana en las primeras décadas del siglo XX. 
Palabras clave: Balún Canán. Rosario Castellanos. Congruencia histórica. Congruencia poética. Congruencia crítica. Cardenismo.

\begin{abstract}
:
This article aims to identify and analyze the presence of historical, poetic and critical data in Balún Canán, by Rosario Castellanos. Much has already been studied about approaches to the life of the author, however, through a sociocritical analysis, this study offers a broad view to other aspects such as the relationship of the story with the Mexican national history, in which it recovers episodes of Cardenismo, the Cristero War and the agrarian reform of the thirties. Regarding poetic and critical congruence, this study shows that is the work with the greatest poetic sense in the prose production of Castellanos, besides that, in it, the writer assumes a marked critical position regarding the behavior of her female characters facing male supremacy, thus inaugurating an early critique of the patriarchal societies of the Mexican province in the first decades of the twentieth century.
\end{abstract}

Keywords: Balún Canán. Rosario Castellanos. Historical congruence. Poetic congruence. Critical congruence. Cardenismo.

\title{
Introducción
}

Después de los conflictos agrarios suscitados durante los años treinta en Chiapas y el resto del país, Rosario Castellanos llegó a la Ciudad de México con sus padres para establecerse en la capital. Fue ella misma quien contó a Emmanuel Carballo que el hecho de haber abandonado Chiapas a los dieciséis años y de vivir lejos de aquella gente (los indígenas) y sus problemas, pensó, la conduciría a escribir sobre asuntos intelectuales, lejanos al mundo indígena, sin embargo, dijo, "la gente que pugnaba por surgir en sus escritos era la de Chiapas" (Carballo, 2003, p.507).

De esta manera, el primer antecedente directo de Balún Canán es la vida de la autora: sus primeros años en Comitán, la muerte de su hermano Mario, la soledad y marginación que enfrentó cuando niña y la relación con su nana Rufina. Esta última representó, para Rosario, todo aquello que la conectaba de forma reflexiva con la tradición indígena en Comitán y su desafortunada historia. 
El doloroso episodio que significó el fallecimiento de su hermano, que la hizo consciente a muy corta edad del dolor que implica la muerte como un hecho natural y que, además, originó un fuerte sentimiento de soledad en ella se encuentra en "Primera revelación", texto anterior a la novela:

Mas esta emblemática novela también tiene otra vertiente, pues la antecede el cuento 'Primera revelación', texto publicado en 1950. Es uno de los primeros relatos de Castellanos publicado en la revista América. Ciertamente esta narración es el antecedente directo y prototexto literario de la novela. Con elementos autobiográficos alude a la muerte temprana del hermano y la vivencia aterrorizada del suceso durante su infancia. También surge la imagen de la nana, que siete años más tarde desarrollaría con especial cuidado. (L. Guerrero, entrevista personal, abril de 2017)

En "Primera revelación", Rosario Castellanos escribió:

Al llegar a la casa cogí un lápiz y con mi letra inhábil, tosca, escribí el nombre de Mario en las paredes del corredor. Mario, en los ladrillos del jardín. Mario, en las páginas de mis cuadernos. Para que si Dios venía alguna vez a buscarlo creyera que estaba todavía aquí. (Castellanos, 1950)

Balún Canán concluye con las siguientes líneas:

Cuando llegué a la casa busqué un lápiz. Y con mi letra inhábil, torpe, fui escribiendo el nombre de Mario. Mario, en los ladrillos del jardín. Mario en las paredes del corredor. Mario en las páginas de mis cuadernos. Porque Mario está lejos. Y yo quisiera pedirle perdón. (Castellanos, 2009, p.286)

El segundo acercamiento a Balún Canán yace en la congruencia histórica (expresada a través de los pasajes cardenistas), poética y crítica, que son materia de interés en este artículo, ya que desde antes de que llegara a la narrativa con esta obra en 1957, Castellanos abordó sensiblemente, desde la poesía, la reconstrucción social y costumbrista de los indígenas de Chiapas, así como la situación de la mujer frente a un entorno dominado por hombres. 
En cuanto a la mujer, Castellanos fue enfática y agudamente irónica respecto al sufrimiento femenino. Gloria Vergara Mendoza (2005) explica que "Rosario deja ver en esas facetas ocultas, una amarga verdad que la poesía desnuda. La mujer sufre y llora por hábito, por herencia, por no diferenciarse de las demás" (p. 297).

Así, en las reminiscencias poéticas de Balún Canán encontramos estas dos dimensiones sobre las que la poeta construyó el relato: la perspectiva íntima como mujer y sus recuerdos como testigo de la vejación a los indígenas suministrada por los terratenientes.

Rosario Castellanos entregó como premisa, en las primeras líneas de su obra, el retrato doloroso y místico de una niña en medio de dos mundos opuestos: el de los indios, con el que simpatiza; y el de los blancos, al que pertenece.

\section{"Mis novelas y cuentos no encajan en el indigenismo"}

Rosario Castellanos rechazó la visión simplificadora, refiriéndose al movimiento literario indigenista, que propone visiones sociales maniqueas y que tiende a idealizar al indígena como bueno, pues ella creía que los indios eran capaces de tener sentimientos y acciones destructivas por la opresión que padecían. Esto es lo que hace de Rosario una voz recurrente y siempre incluida en los estudios sobre el tema.

La Enciclopedia de la Literatura en México señala que la narrativa indigenista tiene estrecha relación con la literatura de contenido social, por lo que los indígenas son la fuente de inspiración para que los escritores realicen denuncias sociales, hurguen en la identidad nacional y aspiren a la justicia:

La narrativa indigenista parte del problema del indio como ente segregado y explotado por los grupos dominantes, y por esto constituye una manifestación de protesta social, económica y política. Su antecedente literario más claro es una novela romántica peruana de 1889: Aves sin nido, de Clorinda Matto de Turner, donde se presenta, en su cruda realidad, la explotación que el poder jurídico, el poder político y el poder eclesiástico hacen del indígena. Más tarde, el Modernismo vio en el indio un elemento exótico. En cambio, gracias a las 
tendencias nacionales que produjo la Revolución, en México se lo empieza a valorar en su contexto actual, de tal modo que las obras indigenistas pretenden presentarlo tal como realmente es. (Pereira, Albarán \& Tornero, 2004)

Castellanos no compartía la idea de que el indio fuera exótico y habló del mundo chiapaneco en el que interactuaban indígenas y mestizos con todos los problemas sociales y económicos de la desigualdad. No pretendió idealizar a ninguno de los dos grupos y apuntó hacia un estudio más general. Observó, estudió, reflexionó y escribió para comprender esas relaciones de víctimavictimario, y aunque el antropólogo mexicano Gonzalo Aguirre Beltrán sostuviera en una reunión del Instituto Nacional Indigenista, el 13 de septiembre de 1971, que la idea de "redimir al indio" no era un apostolado del indigenismo pero sí un tema persistente de la literatura indigenista de autores como Ricardo Pozas, Mauricio Magdaleno y la propia Castellanos, entre otros (De Val \& Zolla, 2014), Balún Canán no pretendió alcanzar tal redención, sino que construyó un relato ficticio con tintes personales a partir de un hecho histórico en México que involucró la lucha de clases indígena-mestizo y que la escritora presenció en su infancia.

Durante las primeras cuatro décadas del siglo XX, la literatura de temática indigenista estuvo ligada, en gran parte, con la Revolución Mexicana y con los estragos que ésta dejó en las comunidades rurales, en las que persistía el colonialismo heredado de los siglos XVI, XVII, XVIII y parte del XIX. Autores como B. Traven, Ermilo Abreu Gómez, Gregorio López y Fuentes, Ricardo Pozas y Mauricio Magdaleno, por mencionar algunos, escribieron de esto en sus obras. Sobre Traven y Castellanos, Martha Robles Otero (1986) explica que la escritora - a diferencia del autor de origen europeo- experimentó un drama más íntimo y personal, mismo que se reitera y confirma en la ambigüedad de los juicios críticos y en el tratamiento de los personajes, pues Rosario, al ser blanco del rechazo paternal por el hecho de ser mujer y, además, de haber sobrevivido como la única hija legítima de los Castellanos, dio cauce a la novela, esto, como resultado de "una mezcla de sincretismo regional respecto a la idea de la muerte, prejuicios 
domésticos y un agudo sentimiento de culpabilidad significado en la narradora infantil” (1986, pp. 152-3).

En El Indio (1935), de Gregorio López y Fuentes; La rebelión de los colgados (1936), de B. Traven; El Resplandor (1937), de Mauricio Magdaleno; y Juan Pérez Jolote (1948), de Ricardo Pozas, es recurrente la figura del indio con características arquetípicas en posiciones desfavorables. En la obra de Rosario Castellanos existe un minucioso cuidado estético para no dotar de adjetivos comunes a los indios y reconstruir su historia a partir de otros hechos históricos como el Cardenismo y la reforma agraria, otorgando un valor agregado dentro de su narración: la perspectiva íntima vista desde una niña, una hija y una hermana. Para Rosario, el indio y la mujer eran igualmente marginados por los hombres que ostentaban el poder.

Si bien Balún Canán ha sido incluida en la narrativa neo-indigenista de nuestro país como la primera obra de una trilogía que comprende las colección de cuentos Ciudad Real (1960) y la novela Oficio de tinieblas (1962) -en los que la autora exploró una visión del mundo indígena y femenino en contraste con las ideas de los grupos capitalistas-, esta obra rompió con la estructura decimonónica de la narrativa realista y ofreció varias voces y estilos en el texto; se desliza de lo lírico y poético al realismo; de lo mágico a lo histórico y real, donde una niña es testimonio de lo que ocurría en Comitán, región donde recogió las vibraciones de la etapa histórica que atravesaba el país en aquel entonces, en la que Lázaro Cárdenas implementó una nueva labor para dignificar la vida de los indígenas.

\section{Lázaro Cárdenas: "El hombre del destino". Congruencia histórica}

Para Rosario Castellanos el hecho de haber nacido y crecido en Chiapas durante un periodo histórico e importante para el rumbo de México determinó las temáticas de su obra narrativa, especialmente en Balún Canán, situada en Comitán y contextualizada durante el mandato de Lázaro Cárdenas - gobierno caracterizado por el impulso de la reforma agraria, el apoyo a la reforma constitucional sobre la educación, la política de masas y la institucionalización nacional, medidas con las buscaba la igualdad económica y social en México-. 
El 30 de mayo de 1970, cinco días después de celebrar su cumpleaños 45, Rosario Castellanos publicó en el diario Excélsior "El hombre del destino". En este artículo de aniversario la escritora hizo una recapitulación de su vida personal y literaria, además de un recuento sobre los libros que había escrito, los premios recibidos, las amistades, así como de la familia que había formado con su hijo, el pequeño Gabriel. La escritora enfatizó en lo que para ella significó el haber vivido su niñez y adolescencia durante la presidencia del general Lázaro Cárdenas:

Y si me preguntara cuál ha sido el hecho más importante [...] fueron las posibilidades ofrecidas, las ventanas abiertas por un gobernante, por su idea de justicia y por su constancia en el deseo de que se aplicara la ley. Me refiero a Lázaro Cárdenas.

Fue este el primer nombre que escuché pronunciar a mis mayores con espanto, con ira, con impotencia. Porque su política no sólo estaba lesionando sus intereses económicos cuando dispuso el reparto agrario en la República y no hizo de Chiapas una excepción- sino que estaba despojándolos de todas las certidumbres en las que se habían apoyado durante siglos. (Castellanos, 2006, p. 482)

Con la Revolución Mexicana se intensificaron los conflictos indígenas en el país. Lázaro Cárdenas asumió la presidencia en los años posrevolucionarios e implementó una política social centrada en la atención y resolución de asuntos obreristas, agraristas e indigenistas. Esta última estaba caracterizada por la misión de integración de indígenas a la educación y a la economía. Por esos años, la comunidad indígena en México representaba al menos la quinta parte de la población nacional y estaba disgregada por todo el territorio en pequeñas comunidades, principalmente en el sur y sureste del país.

Aunque en los años veinte ya se habían realizado repartos agrarios y creado órganos en favor de las comunidades indígenas como el Departamento de Educación y Cultura Indígena de la Secretaría de Educación Pública - que tomaría relevancia hasta el mandato de Cárdenas - y, durante el Callismo, la creación del Banco Nacional de Crédito Agrícola con el fin de otorgar créditos para optimizar y fortalecer la agricultura, el gobierno de Plutarco Elías Calles representó para el agrarismo una fase de estancamiento, pues la inestabilidad política desencadenada por el conflicto 
entre Estado e Iglesia, provocado por las reformas constitucionales en materia educativa y religiosa, concentró la atención del poder en este asunto, especialmente entre 1924 y 1928, lo que permitió a los hacendados recurrir al amparo para proteger sus fincas.

La administración de Lázaro Cárdenas en Michoacán fue clave para su victoria presidencial, pues durante su mandato local mostró sensibilidad para tratar asuntos indígenas y gran empatía con las masas. Como presidente, Cárdenas combatió las ideas conservadoras de "El Jefe Máximo de la Revolución", quien era duro en sus críticas hacia los grupos de izquierda, las huelgas obreras y las revueltas campesinas. Cárdenas rompió permanentemente la relación política que mantenía con Calles.

Everardo Escárcega López (1990) explica que gracias al conocimiento que Lázaro Cárdenas tenía sobre los problemas sociales del país, así como de la organización de movimientos armados, fue posible la implementación inmediata de la reforma agraria, con la que comenzó el reparto de tierras por la vía ejidal, ya que de esa manera evitaría que las comunidades rurales apoyaran las revueltas (p.83).

Ya como el quincuagésimo primer presidente de México, Cárdenas no tardó mucho para poner en acción lo que había sostenido en su discurso como candidato del PNR frente a cientos de campesinos en Tres Palos, Guerrero, el 17 de mayo de 1934:

Para la resolución del problema agrario no entiendo la simple entrega de las tierras a los campesinos. El poder público está obligado a prestar a los ejidatarios toda la ayuda moral y material, para que prosperen económicamente y para que liberen su espíritu de la ignorancia y los prejuicios. En las banderas de la Revolución por la cual hemos venido luchando y por la cual personalmente lo he hecho desde el año de 1913, está escrito que debe entregarse la tierra y la escuela a los campesinos. Soy consciente de la responsabilidad que contraigo con los campesinos, que son los paladines más fuertes Revolución [...] Entregaré a los campesinos el máuser con el que hicieron la Revolución, para que la defiendan, para que defiendan el ejido y la Escuela. (Morales, 2009, p. 971) 
Sobre el artículo 27 constitucional, referido al derecho de propiedad, Lázaro Cárdenas realizó tres modificaciones. En la segunda devolvió a las comunidades indígenas aquellas tierras que pertenecieron a sus ancestros y de las que fueron desposeídos arbitrariamente e incorporó grupos étnicos al proyecto nacional. Todo esto, para dar impulso a la reforma agraria. La voz de Cárdenas se convirtió en un estandarte que se extendió hasta las zonas más recónditas del país, amenazando la economía de los terratenientes.

En Balún Canán, la primera referencia de la política social de Cárdenas como causal de la ruina de los hacendados se encuentra en la visita del tío David a casa de los Argüello. El hombre cuenta al niño Mario y a su hermana:

-¿Qué es el baldillito, tío David?

-Es la palabra chiquita para decir baldío. El trabajo que los indios tienen la

obligación de hacer y que los patrones no tienen la obligación de pagar.

$-\mathrm{iAh}$ !

-Pues ahora se acabó. Si los patrones quieren que les siembren la milpa, que les pastoreen el ganado, su dinero les costará. ¿Y saben qué cosa va a suceder? Que se van a arruinar. Que ahora vamos a ser todos igual de pobres.

$-\dot{\text { TTodos? }}$

-Sí.

-¿También nosotros?

-También. (2009, p.24)

Al contrario, para los indios la ley de Cárdenas era sagrada y debía cumplirse tanto como la de Dios. Edith del Rosario Negrín Muñoz (2008) escribe que "las leyes cardenistas para mejorar las condiciones de vida y conciencia de los indígenas se constituyen en otra especie de texto sagrado que determina el destino de los habitantes del pueblo" (p. 68). En Balún Canán, sobre su encuentro con Cárdenas, Felipe Carranza Pech narra:

-En Tapachula fue donde me dieron a leer el papel que habla. Y entendí lo que dice: que nosotros somos iguales a los blancos [...]. 
- ¿Sobre la palabra de quién lo afirma?

-Sobre la palabra del Presidente de la República [...].

-¿Qué es el Presidente de la República? [...]

$-\dot{\text { Es Dios? }}$

-Es hombre. Yo estuve cerca de él.

-EI Presidente de la República quiere. ¿Tiene poder para ordenar?

Felipe declaró, orgulloso:

-Tiene más poder que los Argüello y que todos los dueños de fincas juntos. (2009, pp. 99100)

Asimismo, Negrín (2008) apunta que la confianza en el presidente de la República había venido a sustituir las antiguas creencias de los hombres del campo. Para muestra, el testimonio de Felipe Carranza, pues el indio evoca de manera recurrente lo que Cárdenas significó para ellos, que era un hombre de justicia y que con él no tendrían que esperar la resurrección de los dioses.

Sobre Lázaro Cárdenas se había formado una especie de sincretismo con todo aquello en lo que los indígenas depositaban su fe, divinidad $u$ hombre, pues después de muchos años alguien, que nunca había pertenecido a su mundo, no los miraba con indiferencia y desprecio, al contrario, les otorgaba derechos como la educación, que hasta ese momento había sido exclusiva de los hombres blancos.

A lo largo del relato, la imagen de Lázaro Cárdenas contrapone dos visiones distintas del entendimiento entre blancos e indios. Para los primeros, el entonces mandatario vino a romper una forma semifeudal de la estructura social de los pueblos, donde el indio, más que acostumbrado, estaba conforme con el trato cruel que le era suministrado por el patrón, es decir, con devoción asumían su rol en la tan marcada y desfavorable posición que ocupaban en la cadena social.

En la novela, César Argüello relata que los indios eran azotados por el patrón antes de dirigirse a sus labores en el campo. Cuenta que aquellos fuetazos no eran con el afán de castigarlos, sino de sacarlos de la somnolencia. Los indios peleaban por ocupar los primeros lugares en la larga fila de los azotes, pues creían que, de llegar al último, el patrón ya no pegaría con la misma fuerza. 
A esto, más adelante, Matilde cuenta a César y Zoraida Argüello que los indios han sido instruidos por Gonzalo Utrilla, inspector agrario, para desacatar sus órdenes, informándoles que ellos ya no tenían un patrón qué obedecer, que no estaban obligados a trabajar para nadie y que los ranchos les pertenecían. A partir de estos acontecimientos, la decadencia de los Argüello es inevitable.

Cuando inició el mandato cardenista el tema de la educación se convirtió en la asignatura pendiente. Los gobiernos que le antecedieron, el Maximato, mantuvieron un sangriento conflicto de carácter religioso con civiles, por lo cual fue prioritaria la resolución de este problema.

El Cardenismo heredó los estragos de la Guerra Cristera, los cuales no pudieron controlar los presidentes anteriores: Emilio Portes Gil, Pascual Ortiz Rubio y Abelardo L. Rodríguez. Entre los años de 1926 y 1929 se registró el auge de este conflicto armando con numerosas muertes en los estados de Michoacán, Zacatecas, Puebla, Jalisco y Morelos, principalmente. En el sureste del país también, a menor medida, se suscitaron revueltas cristeras.

Sin embargo, Cárdenas, con prudencia, continuó con el apoyo a las reformas del artículo 3 constitucional, en las que se establecía una educación socialista, es decir, aquella que debía ser impartida por el Estado y estar exenta de toda doctrina religiosa, fanatismo y prejuicios.

Rosario Castellanos hizo una revisión literaria del pasado ya que, sin hacer mención directa al conflicto cristero, construyó un marco histórico bien definido en el cual permitió reconocer que este momento fue crucial culturalmente - una guerra provocada por la imposición de las leyes en materia religiosa-, pues aunque no fue una guerra nacional y estuvo focalizada en el centro del occidente del país, la lectura que imperó fue que los cristeros eran fanáticos, oscurantistas y retrogradas que no acataban al gobierno central. La incomodidad que resaltó de este acontecimiento surgió de la idea de que era mucho más heroica una revolución donde el pueblo se levantara en armas contra una dictadura, a una guerra en la cual el estado central ejercía el poder con la imposición de una ley y esto provocara tal reacción. Si bien, sí hubo realmente una manipulación por parte de la Iglesia a los cristeros, la verdadera problemática no era el fanatismo, sino que éstos se convertían en enemigos del Estado y de la razón. Los cristeros fueron 
tajantemente vistos como una parte del México profundo que no tenía por qué haber existido. Fue urgente dar conclusión a tal asunto.

En 1934, el Congreso hizo modificaciones al artículo 3 y decretó una educación socialista, en donde la escuela formaría a través de un pensamiento basado en la racionalidad, la exactitud y la vida social. Negó que ésta fomentara la separación de padres e hijos y aseguró que, al contrario, con ella se reafirmaría la conciencia social y verídica alejada del fanatismo. Enseguida, Cárdenas incluyó a los indígenas en el proceso de educación nacional.

A lo largo de la novela, la autora ofreció diversos acercamientos a estas problemáticas y permitió ver en el relato de la pequeña narradora que, a las niñas, lejos de recibir una educación, se les adoctrinaba con base en las creencias religiosas y se les proporcionaba el conocimiento más básico: números y letras, sin dejar de lado la enseñanza de las labores domésticas y la vida de los santos. Evidenció el rigor con el que se pretendía instaurar la nueva escuela.

Lázaro Cárdenas nunca aparece como un personaje físico, es decir, jamás interactúa con los Argüello, pero su palabra y ley son reconocibles y determinantes durante la historia a través del hijo de Jaime Rovelo y el ahijado de César, Gonzalo Utrilla. En un primer momento, ambos personajes pueden llegar a percibirse cercanos a la causa terrateniente, naturalmente, por los nexos de parentesco que existen entre ellos, sin embargo, Rovelo (hijo) y Utrilla - frente a esta idea de poder supremo que se levanta en la figura de Cárdenas - fungen como mensajeros de su palabra y, por ende, de su ley. Jaime Rovelo informa sobre la carta que ha recibido de su hijo:

-El gobierno ha dictado una nueva disposición contra nuestros intereses.

-“Se aprobó la ley según la cual los dueños de fincas, con más de cinco familias de indios a su servicio, tienen la obligación de proporcionarles medios de enseñanza, estableciendo una escuela y pagando de su peculio a un maestro rural."

Mi madre dobla el papel y sonríe con sarcasmo.

-¿Dónde se ha visto semejante cosa? Enseñarles a leer cuando ni siquiera son capaces de aprender a hablar español [...].

-Mi hijo opina que la ley es razonable y necesaria; que Cárdenas es un presidente justo. (2009, pp. 44-5) 
Cuando se notificó a los hacendados sobre la nueva ley de educación para los indígenas, éstos comenzaron a idear las formas para burlar la disposición presidencial. César Argüello conocía muy bien las lagunas del Gobierno, por lo que dispuso como maestro de Chactajal a su sobrino bastardo Ernesto, pese a las dificultades que esto pudiera traer con los indígenas.

Ernesto no sabía hablar tzeltal y sus alumnos no entendían el castellano, pues según los hombres blancos, la lengua castellana era un privilegio exclusivo al que los indios no podían aspirar, no obstante, los años de sometimiento habían seguido su curso y la aculturación fue inevitable. Los hombres tzeltales sabían comunicarse en español y los patrones conocían la lengua del indio.

El caso de los niños era distinto, pues las primeras instrucciones las habían recibido en su núcleo familiar, y aunque algunos de ellos se empleaban en la casa de los patrones como sirvientes, el resguardo de su lengua en los primeros años era la única manera de conservar lo que los blancos no les pudieron arrebatar a sus padres y ancestros.

Para los hombres de la comunidad, el que los pequeños recibieran la educación que por años les fue negada a ellos representaba el comienzo de un largo proceso de reivindicación social, pues Cárdenas, como hombre superior a cualquier otro, no sólo de Chactajal sino del país entero, estaba haciendo justicia y ellos, aunque la primera barrera a vencer fuera la comunicación verbal, estaban conformes con que la ley del presidente se estuviera cumpliendo.

La instauración de la Escuela, como una figura institucional de Gobierno, se erigió no sólo de manera simbólica sobre la clase dominante; para los indígenas, especialmente para Felipe Carranza, levantar la escuela implicaba una ceremonia. Sobre el lugar donde construyeron la escuela, la loma de los Horcones, Felipe escribió:

Para la construcción elegimos un lugar, en lo alto de la colina. Bendito porque asiste al nacimiento del sol. Bendito porque lo rigen constelaciones favorables. Bendito porque en su entraña removida hallamos la raíz de una ceiba ${ }^{1}$ [...]. Ésta es nuestra casa. Aquí la memoria

\footnotetext{
${ }^{1}$ De acuerdo con el Popol Vuh, los dioses creadores sembraron en los cuatro rumbos del cosmos sus respectivas ceibas sagradas: al Este, la ceiba roja; al Oeste, la ceiba negra; al Sur, la ceiba amarilla, y al Norte, la ceiba blanca. Finalmente
} 
que perdimos vendrá a ser como la doncella rescatada a la turbulencia de los ríos. Y se sentará entre nosotros para adoctrinarnos. $Y$ la escucharemos con reverencia. $Y$ nuestros rostros resplandecerán como cuando da en ellos el alba. (2009, pp. 122-3)

En este pasaje existe una concepción poética por parte de Felipe que lo vincula directamente con otro periodo histórico. Negrín (2008) explica que "por el tono ceremonioso del documento, por su forma de describir la naturaleza, por las metáforas que emplea, Felipe parece asumir la herencia de los textos sagrados de la Colonia". (p.66)

La revisión histórica del pasado y el presente en Balún Canán provocó una reflexión respecto hacia dónde se dirigía el futuro.

Si bien Lázaro Cárdenas del Río, el presidente justo, como lo calificó Castellanos, sentó las bases de una política agraria, no logró consolidarla. Su gobierno, de importantes aciertos, no estuvo exento de momentos incómodos. Cárdenas fue acusado de nepotismo. Al concluir su gobierno en Michoacán, el puesto fue tomado por su hermano menor Dámaso Cárdenas, además, el estado fue gobernado también por su hijo Cuauhtémoc Cárdenas Solórzano y su nieto Lázaro Cárdenas Batel.

Los años siguientes al periodo de Cárdenas brillaron por la ausencia de políticas a beneficio de los trabajadores del campo. El gobierno que sucedió, el de Manuel Ávila Camacho, abandonó el seguimiento de las reformas cardenistas y favoreció la propiedad privada. Los terratenientes que habían logrado conservar sus tierras hasta 1940, con el ascenso de Ávila Camacho, tuvieron la seguridad que así sería por un sexenio más.

La Segunda Guerra Mundial propició que la atención del gobierno central se concentrara en asuntos internacionales y el campo quedó relegado a satisfacer las necesidades el mercado externo. El argumento de Ávila Camacho fue que el reparto agrario ya había concluido durante el mandato de Cárdenas. Esto evidenció la falta de planificación del gobierno cardenista para asegurar, en los

sembraron una quinta ceiba al centro de todos estos rumbos, y en sus raíces ubicaron el Xibalbá o Mitnal, que era la morada de los muertos; en su base colocaron el Kab o la tierra que habitamos los seres vivos; y en su fuste y ramas establecieron su morada los dioses; mientras que en la cima de su copa habitaba el origen de todos los dioses en la forma de una magnífica ave Quetzal celestial. 
próximos años, ya sin su líder al frente, que las reformas agrarias en favor de los indígenas continuaran en acción.

La sobreexplotación del campo en respuesta de la demanda del comercio exterior, la marginación racial y la brutalidad con la que miles de indígenas fueron asesinados en Chiapas por años, provocaron la revuelta indígena en la entidad a finales del siglo XX.

Negrín Muñoz asegura que "no se puede entender la situación indígena de los noventa, los legítimos motivos de la rebelión en Chiapas, sin conocer esta obra de Rosario Castellanos" (entrevista personal, enero de 2017).

Entre 1934 y 1940, Lázaro Cárdenas gobernó amenazante para todos aquellos hombres que habían forjado su patrimonio a costa de los indígenas, entre ellos los Castellanos Figueroa, padres de la escritora, y los Argüello, en Balún Canán.

La identidad literaria de Rosario Castellanos estuvo definida y marcada por esta época en la que transcurrió su infancia. Observó la historia sin ningún precedente. Esto es claro por la forma en cómo incorporó la visión propia en su creación literaria. Mostró durante sus primeros años un talento literario básico, es decir, del que no sólo trató de dar testimonio, sino al que transfiguró literariamente de tal manera que, para el lector, este artificio que es el intermediario de la ficción literaria pareciera ser muy real.

\section{Sin Conquista, no hay indio, no hay mestizo}

Es fundamental aclarar la diferencia entre dos términos que a menudo se entienden como uno solo y que ocupan importante valor en esta obra de Castellanos: "indio" e "indígena". Para la definición de estos conceptos, en Los indios en las clases sociales de México, el antropólogo Ricardo Pozas (1971) explicó que no establecer una diferencia entre ambos ha restado relevancia de contraste al sentido despectivo y discriminatorio que se advierte en el primero, y a lo genérico del segundo. Pozas (1971) señaló que se denomina indios o indígenas a los descendientes nativos de América que conservan algunas características de sus antepasados, entre ellos la lengua, la economía y la posición social desfavorable frente al resto de la población (p.11). Por lo anterior, aunado a la 
autovaloración de los conquistadores como una raza superior, fue que la palabra "indio" adquirió la connotación peyorativa y ofensiva que conserva hasta nuestros días en el lenguaje coloquial.

El problema de interpretación para los términos "indio" e "indígena" se debe a la herencia cultural española de la Conquista que relacionó ambos términos y formó, arbitrariamente, la idea de que los hombres indios o indígenas son débiles, ignorantes e inferiores.

Asumidos en su poder y entregados a la absoluta soberbia, los conquistadores ignoraron las tradiciones ancestrales de los pueblos mayas, destruyeron los antiguos templos y sobre ellos erigieron nuevas construcciones, asesinaron a quienes no se sometieron a sus leyes y les arrebataron la tierra.

En 1524, la región de los Altos de Chiapas fue conquistada con la toma del pueblo chamula y en 1528 se fundó Ciudad Real -actualmente San Cristóbal de las Casas-, donde se concentró el poder político-religioso de Chiapas. La Corona española otorgó el título de encomenderos a los conquistadores. Con él, se proclamaron dueños del tributo indígena, sin embargo, con dicho nombramiento, también debían encargarse de protegerlo, enseñarle la doctrina cristiana y pagar un salario mínimo por su trabajo. No fue así.

La supremacía del español no sólo se legitimó con la posesión de nuevo territorio, el tributo y la esclavitud de los nativos; para los conquistadores la supremacía se forjaba con el poder adquirido mediante la fuerza y la brutalidad. Durante la Conquista, la población nativa disminuyó dramáticamente. Caso contrario, el número de alumbramientos en mujeres indígenas incrementó.

El abuso sexual de la mujer indígena, por fuerza o manipulación, representó otro modo de conquista más personal, pues para los hombres blancos las indígenas no eran más que un objetodeseo sin valor. Aquellas que corrían con suerte después de una violación, vivían para contarlo.

Con la repartición de personas durante la Colonia, nacieron los primeros mestizos de la Nueva España. A los hijos de indígena y español con características físicamente predominantes de estos últimos, se les privilegiaba por encima del indígena, de esta manera nació la clasificación de castas. En la novela, César Argüello dice a su sobrino Ernesto: 
-Ahí están las indias a tu disposición, Ernesto. A ver cuándo una de estas criaturas resulta de tu color.

A Ernesto le molestó la broma porque se consideraba rebajado al nivel de los inferiores. Respondió secamente:

-Tengo malos ratos pero no malos gustos, tío.

-Eso dices ahora. Espera a que pasen unos meses para cambiar de opinión. La necesidad no te deja escoger. Te lo digo por experiencia.

$-¿$ Usted?

-¿Qué te extraña? Yo. Todos. Tengo hijos regados entre ellas.

Les había hecho un favor. Las indias eran más codiciadas después. Podían casarse a su gusto. El indio siempre veía en la mujer la virtud que le había gustado al patrón. Y los hijos eran de los que se apegaban a la casa grande y de los que servían con fidelidad. (2009, p.78)

Ante esta idea se fortaleció la noción de superioridad racial y de género que fue más marcada con el transcurso de los años, pues el indígena ocupaba el sitio más bajo de una pirámide social donde la cúspide era ocupada por el hombre europeo. Los que permanecían en medio, generalmente hijos bastardos y mujeres no indígenas, se proclamaron a favor de los hombres blancos y hacendados que, aunque también fueron víctimas de maltrato, apoyaron a la instauración de esta idea histórica respecto a los indígenas.

En el caso de Ernesto y Zoraida, sobrino y esposa de César Argüello, es común encontrar discursos racistas hacia los indios. Ernesto, por ejemplo, dice a los niños indígenas que de nada sirve que los instruya, ya que no dejarán de ser indios. Por otro lado, en el personaje de Zoraida se manifiesta la furia de la clase alta sobre la situación de que los indios se "igualen" ante ellos por expresar sus inconformidades en la misma lengua en que se les ordena y castiga:

[...] Pero el indio contesta en español.

-No vine solo. Mis camaradas están esperándome en el corredor.

Zoraida se replegó sobre sí misma con violencia, como si la hubiera picado un animal ponzoñoso. ¿Qué desacato era éste? Un infeliz indio atreviéndose, primero, a entrar sin 
permiso hasta donde ellos están. Y luego a hablar español. Y a decir palabras como "camarada", que ni César -con todo y haber sido educado en el extranjero- acostumbra emplear. (2009, p.95)

Respecto al uso del lenguaje, Robles Otero explica (1986) que, si bien, el indio no hablaba regularmente con el amo en "castilla", cuando lo hacía utilizaba el "vos" - singularidad lingüística del sur de México-, en el que a través del tiempo se reflejó "la lucha de clases, la diferencia étnica y la dudosa familiaridad" (1986, p. 154).

Es evidente la posición desfavorable de los indios, sin embargo, en Balún Canán tienen una particularidad; ante todo el sufrimiento y vejación que han padecido por siglos, los indios de la novela expresan sus sentimientos de resentimiento y venganza con traición, es decir, rompen con una idea preconcebida socialmente de que el indio es "bueno" por el hecho de sufrir.

Respecto a mencionadas características de los indios de Balún Canán, Geney Beltrán Félix expresa que esto se debe fundamentalmente al poder de observación de la autora y la capacidad de ver la realidad sin ideas previas, es decir, la percepción que la escritora tenía de los indígenas se formó por contacto directo desde la infancia y no estuvo influida por la literatura. El crítico literario enfatiza en que Castellanos dotó a sus personajes de gran vehemencia gracias a que observó la realidad desde una posición desfavorable, pues quien no tiene poder, antes de dar un paso, debe mirar detenidamente. Rosario dejó fluir su voluntad en el dominio de la visión (entrevista personal, agosto de 2017).

A Cesar Argüello lo toma por sorpresa el comportamiento cobarde y traidor de los indios cuando se convierte en blanco de su venganza. En la segunda parte de la novela se narra un acontecimiento que tiene que ver con la destrucción total de la cosecha a causa de un incendio provocado por los indios para perjudicar a su patrón. Este hecho obliga a los Argüello a huir de la hacienda Chactajal y culmina con la muerte de Ernesto.

Después de la orden de Cárdenas sobre la educación para los indígenas, este es el segundo golpe certero para derrumbar a los Argüello. 


\section{Congruencia poética}

Balún Canán reúne la virtud poética de la autora a su gran maestría narrativa. A lo largo de la historia, Rosario ofreció diversos pasajes donde reconstruyó situaciones con la fuerza poética de su palabra. Las principales influencias de Rosario Castellanos fueron los poetas José Gorostiza, Gabriela Mistral y Concha Urquiza, además de textos como la Biblia y otros de carácter religioso.

Durante la entrevista con Emmanuel Carballo, fue la escritora quien reconoció la fuerte influencia de la poesía en su prosa y expresó que es en la primera parte de Balún Canán (2009) donde existe este influjo; además, dijo, esta obra no podría considerarse prosa ya que está llena de imágenes que se ajustan a la musicalidad, y que, si hubieran sido publicadas aisladamente, no podrían considerarse relatos (2003, p. 506).

Sobre estas figuras referidas por la autora, Gloria Vergara Mendoza explica que, en Balún Canán, hay partes, especialmente las de la narradora, donde existen imágenes poéticas que corresponden a la infancia y la soledad, y, además, también es posible identificar los matices poéticos de Rosario cuando se describen algunos lugares y personalidades, es decir, por un lado, hay armonía y, por el otro, un importante énfasis descriptivo vinculado a su poética (entrevista personal, mayo de 2017).

En la primera parte, la niña narradora describe su núcleo escolar de la siguiente manera:

Las paredes del salón de clase están encaladas. La humedad forma en ellas figuras misteriosas que yo descifro cuando me castigan sentándome en un rincón. Cuando no, me siento frente a la señorita Silvina en un pupitre cuadrado y bajo. La escucho hablar. Su voz es como la de las maquinitas que sacan punta a los lápices: molesta pero útil. Habla sin hacer distingos, desplegando ante nosotras el catálogo de sus conocimientos. Permite que cada una escoja los que mejor le convengan. Yo escogí, desde el principio, la palabra meteoro. Y desde entonces la tengo sobre la frente, pesando, triste de haber caído del cielo. (2009, p.12) 
¿Qué sugiere tal descripción de la profesora hecha por una niña? Tomando en cuenta que, hasta la redacción de esta novela, la producción literaria de Castellanos mayormente era poesía, estas líneas muestran el notable recurso poético referido por Vergara. En la descripción se percibe a una pequeña con un atrevido lenguaje que, si bien es sarcástico, ejerce un juicio certero y expresa la curiosidad imaginativa de una pequeña "descifrando figuras misteriosas en las paredes húmedas". Más adelante se describe a César Argüello:

César no era de los hombres que se desarraigan. Desde donde hubiera ido, siempre encontraría el camino de regreso. Y donde estuviera siempre sería el mismo. El conocimiento de la grandeza del mundo no disminuía el sentido de su propia importancia. Pero, naturalmente, prefería vivir donde los demás compartían su opinión; donde llamarse Argüello no era una forma de ser anónimo; donde su fortuna era igual o mayor que la de los otros. (2009, p.75)

Por la retórica de este fragmento de la segunda parte, el sentido de prevalencia adquiere tintes poéticos cuando el narrador omnisciente describe al padre de la niña. En estas líneas quedan contenidas dos características de aquel hombre: la fuerza y el temor. Este último contrasta con todo lo que, en la narración, parece describir a la familia Argüello: el valor, que termina vencido por la justicia histórica.

La poesía de Castellanos evoca los recuerdos de su infancia católica y las historias mágicas de la cosmovisión de los indígenas chiapanecos.

Rosario Castellanos expresó que en Balún Canán la niña narradora se mueve en un mundo lo suficientemente fantástico como para que en él funcionen las imágenes poéticas, de ahí el profundo respeto por las historias y los paisajes del mundo indígena, pues advirtió que este último tiene semejanzas con el mundo infantil.

El paisaje poético de Balún Canán se convierte en una forma valorar la tradición oral de los indígenas, en este caso a la nana. Habrá que recordar que para los tzeltales el equilibrio con la naturaleza es primordial y representa una comunión de religiosidad. Cada elemento de la 
naturaleza: montaña, viento, río o piedra conforman un paisaje poético en la obra, el cual es evidente cuando la escritora inaugura la segunda parte, donde el viento se convierte en un instrumento poético pues, de acuerdo con la nana, es uno de "los nueve guardianes" de Comitán.

Asimismo, la remembranza del pasado es recuperada en crónicas de tonos poéticos donde no sólo se fundan las ciudades, también la palabra que adquiere un valor supremo y, de la misma forma que el viento, se mezcla con la naturaleza del paisaje poético de Castellanos.

En la novela hay narraciones que generalmente no podrían ser hechas por una niña, puesto que implican un estudio profundo de la historia y la lengua, sin embargo, en la segunda parte hay un narrador que descifra estos episodios para ofrecer un amplio panorama respecto a la apropiación de la tierra.

La tercera parte de la novela retoma el testimonio de la niña y, a partir de ese momento, se revela un universo onírico y fantasioso, en el que los anhelos se convierten en sueños. Es la niña quien imagina las posibilidades de permanecer siempre junto a su nana:

Cuando cierro los ojos en la noche se me representa el lugar donde mi nana y yo estaremos juntas. La gran Ilanura de Nicalococ y su cielo constelado de papalotes. Habrá algunos que vuelen a ras del suelo por falta de cordel. Otros que desde arriba se precipitarán con las varas quebradas y el papel hecho trizas. [...] Y mi nana y yo quedaremos aquí sentadas, cogidas de la mano, mirando para siempre. (2009, p. 240-1)

De la misma forma en que la relación con su hermano Mario Benjamín influyó en las temáticas de la poesía de la escritora, el pequeño Mario, hermano de la niña narradora de Balún Canán, influyó también en el tono y la carga sentimental de la palabra emitida por la pequeña.

La narradora, al perder a su hermano, experimenta la soledad y la manifiesta con sus palabras. Ella, que siempre ha estado inmersa en la indiferencia total, la asemeja a la misma muerte de su hermano e inocentemente desea que ésta no sea tan cruel como la que ella padece en vida. El tono poético de esta expresión permite entrever una experiencia personal. 
Vergara explica (entrevista, 2017) que la expresión poética de la soledad en la novela se concreta puntualmente en la pérdida de Mario, así, cuando la niña vuelve a la casa y el hermano y la nana ya no están, ella desahoga su dolor rayando las paredes de la casa, forma similar en que la nana, con el mismo sentimiento de pérdida, abre la narración, sólo que, a diferencia de ésta, la niña narradora ya no tiene quién la escuche porque sus únicos iguales eran el hermano y la mujer indígena. Nadie más.

\section{Congruencia crítica}

Balún Canán es el sitio de un mundo femenino concebido por Rosario Castellanos, reflejo de la sociedad de principio del siglo XX. En la novela, la escritora evidenció cuáles son, desde entonces, las prácticas que ponen en desventaja a las mujeres no sólo a niveles políticos y culturales, también a niveles humanos. Mostró una galería de mujeres que juegan distintos roles impuestos desde la educación, la casa, las normas y que incluso, inciden en la manera de verse a sí mismas.

Y el mundo, en Rosario Castellanos, está cifrado por su feminidad; de allí una forma frecuente en su equilibrio creador: a más íntima la búsqueda de su identidad, mayor certeza de reflejar la condición femenina. Su vida funge como espejo de las mujeres de su tiempo mediante la expresión de la dualidad aceptación-resistencia de lo regido por la figura ideal y del universo de lo inmediato. (1986, p. 148)

Si bien, en la identidad femenina conformada por las mujeres de Balún Canán persiste un tono autobiográfico, en ella también se inscribe la influencia de todas aquellas inquietudes de Rosario durante sus estudios profesionales, lo que le permitió un magistral uso de la retórica en el discurso. De esta manera, en Balún Canán se percibe la fuerza de la palabra ejercida sobre las mujeres en un mundo de terratenientes, en donde cada una mantiene un comportamiento apegado a las normas y al recato que, finalmente, termina por corromperse. En este abanico de mujeres se encuentran la niña narradora y su madre, Zoraida. En la relación, que debería ser naturalmente afectiva, se muestra la histórica idea cultural de la esposa como depositaria del orgullo del hombre, la cual no 
siempre era válida en el caso de concebir a una hija ${ }^{2}$. El rechazo cobraba tal importancia que, también, era transmitido entre las mismas mujeres, de madres a hijas, hasta convertirse en una absoluta resignación frente a su desvalorado papel e irrelevante participación en asuntos de la vida pública, en los que no eran incluidas.

El desplazamiento de la mujer se convirtió en una práctica habitual de los hombres, donde a ellas se les hizo saber que su lugar estaba "detrás de ellos". Rosario recuperó con sentido irónico esta costumbre cuando la niña cuenta sobre una salida familiar:

Los mayores cruzan apuestas. Los niños corren, arrastrados por sus papalotes que buscan la corriente más propicia. Mario tropieza y cae, sangran sus rodillas ásperas. Pero no suelta el cordel y se levanta sin fijarse en lo que le ha sucedido y sigue corriendo. Nosotras miramos, apartadas de los varones, desde nuestro lugar. (2009, p. 22)

La participación femenina queda relegada a la de un testigo oculto, incapacitado de inmiscuirse en asuntos tan cotidianos como la convivencia. Es quizá por esto, que más adelante la niña es quien tiene el atrevimiento de robar las llaves del oratorio, como muestra de una oposición subversiva a lo que culturalmente ya ha estado estipulado en la conducta femenina.

A partir de la niña, "Rosario aprovechó el ambiente para esbozar algunos personajes secundarios de gran riqueza literaria, cuyos prejuicios y desvaríos reflejan la marcada herencia colonial de un medio aislado al resto del país" (1986, p. 160) y como ejemplo, las tres primas de César Argüello: Francisca, la mujer temida que nunca se casó; Romelia, la divorciada; y Matilde, "la solterona" de carácter introvertido que se involucra en una relación incestuosa con su sobrino Ernesto. Estas tres mujeres conservan una finca en Palo María.

Cada una de estas mujeres representa una identidad femenina socialmente castigada. Francisca es una mujer fuerte que, después del conflicto agrario, pierde la razón utilizando la

\footnotetext{
${ }^{2}$ Fue en el siglo XIX que Nettie Stevens, genetista estadounidense, descubrió los cromosomas XY, los cuales determinan el sexo del cigoto durante la gestación y únicamente se encuentran en la carga genética masculina, sin embargo, por mucho tiempo y aún después de este avance científico, el hecho de no concebir al varón durante el primer embarazo, en algunas comunidades de provincia, se atribuía a una anomalía en la fertilidad femenina, que generalmente desencadenaba una apatía hacía la primogénita, como el caso de niña narradora de Balún Canán.
} 
brujería para amedrentar a los indios y alejar de sus propiedades cualquier amenaza de despojo. Es ella la imagen de la mujer fuerte que, aunque respetada, no deja de ser señalada por su conducta reacia. En Romelia se halla la imagen de la divorciada, mujer que ante tal agravio es señalada por carecer de compañía y el cuidado de un hombre. La única solución "médica" que encuentra para el alivio de sus enfermedades es la reconciliación con su marido. Finalmente, en Matilde está la imagen de la mujer que infringe la ley natural enamorándose de su sobrino Ernesto y, por consecuencia, es castigada cuando queda embarazada. Después del asesinato de Ernesto, se descubre su amorío con él y es desterrada de la casa Argüello perdiéndose en la selva donde después, presuntamente, es capturada por el dzulúm.

Son las mujeres quienes manifiestan completo apego a las normas sociales. En el caso de Zoraida se ejemplifica aquello a lo que se refirió Castellanos años más tarde cuando concibió a la mujer como cómplice de su verdugo, al que no reconoció como enemigo natural. Zoraida es una nueva burguesa que justifica a César de todos los actos que la denigran como mujer, madre y esposa. Sobre las infidelidades de César, su Marido, Zoraida expresa:

Habría de ser estúpida para ignorar un hecho tan evidente. Además, toda mujer de ranchero se atiene a que su marido es el semental mayor de la finca. ¿Qué santo tenía cargado Zoraida para ser la única excepción? Por lo demás no había motivo de enojo. (2009, p. 79)

No sólo describió a la sociedad terrateniente en Balún Canán, Rosario Castellanos contó sobre la vida y las costumbres de las comunidades indígenas de Chiapas. A través del testimonio de Juana, la esposa de Felipe Carranza Pech, la autora retrató la vida marital de los indígenas.

Para ellos, el matrimonio representa un ritual de comunión que implica llevar a cabo todas las prácticas del cortejo como el pañuelo colorado sobre la falda de la joven, el tiempo en que cada uno sirve a los padres del otro y el conocimiento y ejecución de las labores del campo y el hogar. En las familias indígenas, son los padres de ambos quienes acuerdan el matrimonio de los jóvenes después de que estos últimos hayan logrado la aprobación de los suegros. Cuando Juana y Felipe pasaron las pruebas de consentimiento y se casaron, el comportamiento marital ya no se diferenció, 
salvo a las limitaciones de su condición económica, al de una pareja de hacendados. Juana adoptó una actitud sumisa frente a la imagen de su esposo e inmediatamente, ante la imposibilidad de tener hijos, fue a ella a quien se le acusó de tener el "vientre seco" a consecuencia de un hechizo de los brujos de la región.

Las mujeres indígenas son aún más desvalorizadas que las mestizas, por lo que, para los hombres, el contraer matrimonio con una india ni siquiera es una opción, sin embargo, la posesión de alguna de ellas enaltece su orgullo y la fuerza de ejercer su poder, ya que el hecho de poseer a una significa arrebatar al indio la dignidad y el derecho a ejercer su hombría.

\section{Conclusión}

Como se ha expuesto, en las páginas de Balún Canán se cuenta, desde una visión personal -la de su autora-, una parte importante de la historia nacional. En esta novela, Rosario Castellanos logró configurar un relato lo suficientemente complejo para que, en él, la historia, su poesía y la agudeza crítica que la caracterizó, parecieran ser solo tres aspectos al servicio del quehacer literario. Sin embargo, este análisis permite mirar más allá y dar cuenta que estos aspectos funcionan como las bisagras que articulan el relato, pues al mismo tiempo que la escritora vinculó la historia contemporánea a la cosmovisión indígena tzeltal, evidenciando los contrastes de ambas formas de entender y vivir en el mundo, recurrió a su talento poético y puso énfasis en qué situaciones han relegado a la mujer y qué tan cómplices han sido de su propia marginación.

De esta manera, Rosario Castellanos inició, con esta novela, una crítica temprana a las sociedades patriarcales y la sumisión femenina en la provincia mexicana a inicios del siglo XX, y, aunque es ampliamente catalogada como una escritora feminista, su visión rebasó las barreras del género y se instaló en todas las dimensiones de la desigualdad; la prueba es que dejó esta obra como referencia. Balún Canán, además, posee elementos estéticos y literarios tan valiosos como los que ostenta la producción literaria de escritoras como Sor Juana Inés de la Cruz.

En sólo diez meses, tiempo que tardó la redacción de la novela, y alentada por Sergio Magaña y Emilio Carballido, Castellanos echó mano de los recuerdos, los documentos, las vivencias, 
las voces, la tierra, la nostalgia, la historia, el dolor y la muerte para crear una de las novelas más significativas de su obra y de las letras mexicanas.

\section{Referencias}

Carballo, E. (2003), Protagonistas de la Literatura Mexicana. 5ta. edición, México: Porrúa.

Castellanos, R. (2009), Balún Canán. 5ta. edición, México: FCE.

Castellanos, R. (2006), Mujer de palabras. vol. II, México: Conaculta.

Castellanos, R. (1950), “Primera revelación”. en Revista América, México.

De Val, J. y Zolla, C. (2014), Documentos Fundamentales del indigenismo en México. México: Publicaciones Fomento Editorial.

Escárcega, E. (1990), Historia de la cuestión agraria mexicana. El cardenismo: un parteaguas histórico en el proceso agrario. 1934-1940. México: Siglo XXI.

Morales, M. (2009). Lázaro Cárdenas del Río. Un mexicano de tres siglos. Revista Letras de Oro, capítulo $\begin{array}{lllll}\text { VII. } & \text { Recuperado de } & 2017\end{array}$ http://www.diputados.gob.mx/LeyesBiblio/muro/pdf/cardenas perfil.pdf

Negrín. E. (2008), "Voces y documentos en Balún Canán", en Revista semestral del Centro de Estudios Literarios. XIX(2) 57-75.

Pereira, A; Albarrán, C; Rosado, J; Tornero, A. (2004), Narrativa indigenista. Enciclopedia de Literatura en México. [Versión electrónica]. Recuperada de http://www.elem.mx/estgrp/datos/99

Pozas, R.; De Pozas, I. (1971), Los indios en las clases sociales de México, México: Siglo XXI.

Robles, M., (1986), La sombra fugitiva. Escritoras en la cultura nacional. Tomo II, México: UNAM/Instituto de Investigaciones Filológicas/Centro de Estudios Literarios (Letras del Siglo XX).

Vergara, G. (2005), "Miradas que se cruzan”, en Estudios sobre las Culturas Contemporáneas, Vol. XI, (22). 